\title{
HLA studies in IgM rheumatoid-factor-positive arthritis of childhood
}

\author{
L. E. CLEMENS,${ }^{1}$ E. ALBERT,${ }^{2}$ AND B. M. ANSELL ${ }^{3}$ \\ From the ${ }^{1}$ Juvenile Rheumatism Unit, Taplow, the ${ }^{3}$ Clinical Research Centre, Harrow, and the ${ }^{2}$ National \\ Reference Tissue Typing Laboratory, Munich
}

SUMMARY The clinical course of children with IgM rheumatoid-factor-positive chronic arthritis closely resembles that of seropositive rheumatoid disease in adults. The frequency of HLA DR4 is known to be increased in adults with seropositive rheumatoid arthritis, but the first major report on childhood arthritis did not suggest a correlation, though only 8 seropositive cases were included. Fifty-two children with polyarthritis beginning before the age of 16 who persistently carried IgM rheumatoid factor were studied. HLA DR4 was present in $60 \%$ of these children but was found in only $29 \%$ of 93 patients with seronegative juvenile arthritis and $27 \%$ of a normal adult population. These results suggest immunogenetic similarities in patients with seropositive arthritis irrespective of age of onset.

Only a small proportion of patients with childhood onset arthritis persistently carry IgM rheumatoid factor (RF). A recent computer analysis of 148 patients with juvenile chronic arthritis (JCA) seen within 3 months of onset showed that $6 \%$ carried IgM, RF. and their disease was characterised by a polyarticular onset progressing rapidily to bony erosions. ${ }^{1}$ Seropositivity is known to be more common with increasing age of onset, and there is a marked female preponderance in patients affected. ${ }^{2}$

The association of HLA DR4 with adult rheumatoid arthritis is well established..$^{3-5}$ However. Stastny and Fink reported different HLA D associations in adults and children ${ }^{6}$ and noted HLA DR4 in only 1 of 8 children with seropositive arthritis compared with $70 \%$ in adults. This apparent difference between adult- and childhood-onset RF-positive arthritis prompted us to study HLA antigen distribution in a larger group of such patients.

\section{Materials and methods}

Patients. Fifty-two children, 43 girls and 9 boys. whose arthritis began before the age of 16 were studied. All fulfilled the criteria for diagnosis of juvenile chronic arthritis, ${ }^{7}$ and persistently carried IgM rheumatoid factor, as shown by repeatedly positive results, over the first year of illness, for both the

Accepted for publication 7 July 1982.

Correspondence to Dr B. M. Ansell, Division of Rheumatology, Clinical Research Centre, Northwick Park Hospital, Watford Road. Harrow, Middlesex HA1 3UJ. latex test using human $\operatorname{IgG}$ substrate and sensitised sheep red cell tests using rabbit $\mathrm{IgG}$.

Clinical data. Clinical, radiological, and laboratory measures of disease activity and severity were assessed at the onset of disease and at 2 and 5 years. An attempt was made to correlate findings with HLA types and to identify clinical subgroups.

Controls. HLA antigen frequencies for English Caucasians from Histocompatibility Testing $1980^{\star}$ were used to provide normal control figures, with the population size being reduced to equal that of the patient group. As part of a programme of genetic studies in juvenile chronic arthritis we have typed 93 children with seronegative JCA, and these patients provided a seronegative control group.

HLA typing. HLA A, B, C, and DR typing was carried out on peripheral blood lymphocytes by a standard complement-dependent cytotoxicity method. Twelve A-locus, 16 B-locus, $7 \mathrm{C}$-locus, and 10 DR-locus antigens were tested.

Statistical analysis. Differences in antigen frequencies between the patient and control groups were tested for significance by Fisher's exact test, corrected for the number of antigens tested. The same method was used to evaluate associations between clinical features and HLA antigens.

\section{Results}

Altered antigen frequencies. Several antigens showed altered frequencies (Table 1). The only one to show significance was HLA DR4, which was present in 
Table 1 HLA antigens showing altered frequency in 52 patients with seropositive childhood arthritis compared with normal controls and seronegative juvenile chronic arthritis

\begin{tabular}{lllll}
\hline Antigens & $\begin{array}{l}\text { Seropositive } \\
\text { childhood } \\
\text { arthritis } \\
(n=52) \\
\%\end{array}$ & $\begin{array}{l}\text { Seronegative } \\
\text { JCA } \\
(n=93) \\
\%\end{array}$ & $\begin{array}{l}\text { Normal } \\
\text { controls } \\
\%\end{array}$ & $\begin{array}{l}\text { p value } \\
\text { (corrected) }\end{array}$ \\
& & & & \\
\hline DR1 & 25 & 13 & 13 & NS \\
DR2 & 10 & 25 & 19 & NS \\
DR4 & 60 & 29 & 27 & $0 \cdot 007$ \\
DR5 & 21 & 28 & 19 & NS \\
B8 & 44 & 26 & 29 & NS \\
B27 & 15 & 10 & 8 & NS \\
\hline
\end{tabular}

$60 \%(\mathrm{p}($ corrected $)=0 \cdot 007)$ of seropositive subjects, which contrasted with the first 93 typed seronegative patients, of whom $29 \%$ carried HLA DR4. The control group of normal adults showed a frequency of $27 \%$ for this antigen. There was an increase in HLA B8, B27, and DR1 and a decrease in HLA DR2 in the group under study, but none of these was statistically significant.

Family studies. The parents and siblings of 16 patients were also studied to define HLA haplotypes and homozygosity. In 5 families there was a history of adult rheumatoid arthritis, a grandparent in 4 , and uncle in one; one of these cases was seen and confirmed as seropositive rheumatoid arthritis. There were no cases of affected sibling pairs. Ten of the 16 probands were DR4-positive, 2 being homozygous, but DR4 did not appear to be associated with any particular haplotype. Five carried the B8, DR3 haplotype. In 4 families there were siblings who did not have disease but shared both haplotypes with the proband.

Clinical parameters. The mean age of onset was 10.9 years ( 3 to 15 ); $25 \%$ of patients had a family history of rheumatoid arthritis. A review of $x$-rays showed that all had developed widespread erosions within 5 years of onset of their disease, with most having these changes present at 2 years. Long-acting drugs had been given to $85 \%$ of patients within the first 5 years of disease; toxic reactions to them had occurred in $23 \%$ of cases. Arthroplasty, usually of the hip, had been performed in $39 \%$ of our patients. A comparison of findings in patients who were DR4-positive with those who were negative revealed 2 trends (Table 2); in particular, rheumatoid nodules were more frequent in DR4-positive patients, and toxicity to long-acting drugs was more common in DR4-negative patients. There was no difference with respect to mean age at onset, family history of rheumatoid arthritis, and frequency of arthroplasty.

Toxicity to long-acting antirheumatic drugs. Toxic reactions requiring treatment to be stopped occurred
Table 2 Clinical findings in HLA DR4-positive and HLA DR4-negative patients with seropositive childhood arthritis

\begin{tabular}{lll}
\hline & $\begin{array}{l}\text { DR4-positive } \\
(n=31)\end{array}$ & $\begin{array}{l}\text { DR4-negative } \\
(n=21)\end{array}$ \\
\hline Mean age onset & $11.4 \mathrm{yr}$ & $10 \cdot 5 \mathrm{yr}$ \\
Family history RA & $23 \%$ & $29 \%$ \\
Arthroplasty & $40 \%$ & $40 \%$ \\
Nodules & $39 \%$ & $19 \%$ \\
Toxicity to long-acting drugs & $20 \%$ & $38 \%$ \\
\hline
\end{tabular}

Table 3 Toxic reactions to gold and penicillamine in seropositive childhood arthritis

\begin{tabular}{llllll}
\hline Drug & $\begin{array}{l}\text { Number } \\
\text { of } \\
\text { courses }\end{array}$ & $\begin{array}{l}\text { Toxic } \\
\text { reactions }\end{array}$ & $\begin{array}{l}\text { Proteinuria } \\
\text { (number } \\
\text { DR3 } \\
\text { positive) }\end{array}$ & $\begin{array}{l}\text { Rash } \\
\text { (number } \\
\text { DR3 } \\
\text { positive) }\end{array}$ & Other \\
\hline Gold & 29 & 8 & $2(0)$ & $6(4)$ & 0 \\
Penicillamine & 18 & 6 & $1(0)$ & $1(0)$ & 4 \\
\hline
\end{tabular}

during 8 of 29 courses of gold in 27 children and 6 of 18 courses of penicillamine in 18 children (Table 3 ). Proteinuria greater than $2 \mathrm{~g}$ daily developed in 3 patients ( 2 on gold, one on penicillamine); none carried DR3. Seven patients developed a rash (6 on gold, one on penicillamine); 4 of these patients did carry DR3. Two patients developed side effects to both penicillamine and gold; the toxic reactions were dissimilar in both cases; one patient was DR3positive. These numbers are too small to allow statistical evaluation.

\section{Discussion}

Clinically the heterogeneity of childhood arthritis is well recognised, and HLA studies have revealed significant alterations in antigen frequencies in several subgroups. ${ }^{6-12}$

The strongest association is that of HLA B27 with juvenile ankylosing spondylitis ${ }^{13}{ }^{14}$ and postdysenteric arthritis. ${ }^{15}$ Examination of clinically defined subgroups of JCA has revealed other associations. Glass et al. ${ }^{9}$ found an increased frequency of HLA DR5 in patients with early-onset pauciarticular disease, chronic iridocyclitis, and positive antinuclear antibodies. Stastny and Fink ${ }^{6}$ found the HLA D antigen TMo in $46 \%$ of their patients with persistent pauciarticular arthritis, while Morling et al. ${ }^{10}$ described increased HLA DW5 and DW8 and decreased DW/DR-2 in their patients in this subgroup. Høyeraalet al. ${ }^{11}$ in a study of 77 patients found increased DR5 and DR8 in those with a pauciarticular onset but did not divide their group into persisting pauciarticular and progression to polyarthritis. An increase in antigens HLA B27 and B17 has been 
described in juvenile psoriatic arthritis, and it has been suggested that presence of B17 is associated with mild arthritis. ${ }^{16}$

Our results in patients with seropositive childhood arthritis differ from those of Stastny and Fink, who found HLA DR4 in only one of their 8 latex-positive polyarticular patients. ${ }^{6}$ This low frequency of HLA DR4, compared with $60 \%$ in our group, may be entirely due to the small number of patients included, but the factors of race and patient selection must also be considered. All our patients were Caucasian and had persistently positive tests for rheumatoid factor by both latex and sensitised sheep red cell tests; most had been followed up for at least 5 years. We purposely excluded patients with an intermittently weakly positive latex or red cell agglutination test or a single positive result. Our findings and those of Høyeraal et al., ${ }^{11}$ who showed an increased frequency of HLA DR4 in a small group of children with Rose-Waaler-positive polyarthritis, suggest immunogenetic similarities in adults and children with seropositive disease.

The potential severity of seropositive polyarthritis in childhood has been recognised for some time,${ }^{17}$ but only recently has the radiological progression and response to long-acting drug therapy been reported. ${ }^{18}{ }^{19}$ The high incidence of destructive joint disease, arthroplasty, and the need for long-acting antirheumatic drugs in our group highlights the aggressiveness of the disease and contrasts with the natural history of seronegative polyarticular JCA. ${ }^{17}$

We sought HLA associations in our patients which might be useful in predicting disease prognosis or response to therapy. The recognised association between HLA DR3 and the development of proteinuria in adults with rheumatoid arthritis treated with gold or penicillamine ${ }^{20}$ prompted us to examine antigen frequencies in our patients with toxic reactions to these long-acting drugs. Although toxic reactions occurred during one-quarter of the gold courses and one-third of the penicillamine courses, there were insufficient cases of proteinuria or rash to allow significant antigen associations to be demonstrated.

No single antigen was associated with a specific prognosis; in particular the presence of HLA DR4 did not correlate with disease severity as determined by the need for arthroplasty. Homozygosity for DR4 has been reported to be associated with 'extraordinarily severe disease' in adult rheumatoid arthritis. ${ }^{21}$ Two patients in our group, found to be DR4 homozygotes by family typing, suffered particularly severe disease, requiring multiple arthroplasties within 5 years and, in one, replacement of the aortic valve. However, disease of similar severity was present in DR4 heterozygotes and DR4-negative patients.

A further finding of interest from the families studied was the identification of 4 healthy siblings who shared both haplotypes with affected probands. This is in agreement with studies of rheumatoid arthritis and other HLA-linked diseases and suggests that environmental factors and gene loci distant from the major histocompatability complex may contribute to disease susceptibility.

This study confirms that arthritis in childhood associated with IgM rheumatoid factor is frequently severe, destructive, and progressive and establishes that there are immunogenetic similarities in patients with seropositive arthritis irrespective of age of onset.

This work was supported in part by the Stiftung Volkswagenwerk and the Medical Research Council.

\section{References}

1 Ansell B M, Fink C, Wood P H N. Juvenile arthritis in England: a long term follow-up. Arthritis Rheum 1980; 23: 673 (abstr).

2 Hanson V, Drexter E, Kornreich $H$. The relationship of rheumatoid factor to age of onset in juvenile rheumatoid arthritis. Arthritis Rheum 1969; 12: 82-6.

3 Panayi G S, Wooley P H. B lymphocyte alloantigens in the study of the genetic basis of rheumatoid arthritis. Ann Rheum Dis 1977; 36: 365-8.

4 Stastny P. Association of the B-cell alloantigen DRW 4 with rheumatoid arthritis. $N$ Engl J Med 1978; 298: 869-71.

5 Panayi G S, Wooley P H, Batchelor J R. Genetic basis of rheumatoid disease: HLA antigens, disease manifestations, and toxic reactions to drugs. $\mathrm{Br}$ Med J 1978; ii: 1326-8.

6 Stastny P, Fink C W. Different HLA-D associations in adult and juvenile rheumatoid arthritis. J Clin Invest 1979; 63: 124-30.

7 Brewer E J, Bass J, Baum J, et al. Current proposed revision of JRA criteria. Arthritis Rheum 1977; 20 (suppl 2): 195-9.

8 Baur M P, Danilovs J A. Joint report: population analysis of HLA-A, B, C, DR and other genetic markers. In: Terasaki P I, ed. Histocompatibility testing. Los Angeles: UCLA Tissue Typing Laboratory, 1980: 958-9.

9 Glass G, Litvin D, Wallace K, et al. Early-onset pauciarticular juvenile rheumatoid arthritis associated with human leucocyte antigen DR W5, iritis and antinuclear antibody. J Clin Invest 1980; 66: 426-9.

10 Morling N, Hellesen C, Jakobsen B K, et al. HLA, B, C, D, DR antigens and primed lymphocyte typing (PLT) defined DP-antigens in juvenile chronic arthritis. Tissue Antigens 1981; 17: 433-41.

11 Høyeraal $\mathrm{H} \mathrm{M}$, Forre $\mathrm{O}$, Doblong $\mathrm{J} \mathrm{H}$, et al. HLA-antigens in juvenile rheumatoid arthritis patients. Association between immunoglobulin $M$ rheumatoid factor production and the HLA-DR4 antigen. Abstr 0673, 15th International Congress Rheumatology. Rev Rhum Mal Osteoartic 1981.

12 Morling N, Astrup L B, Friis J, et al. HLA-D associations in juvenile chronic arthritis. Abstr 0672, 15th International Congress Rheumatology. Rev Rhum Mal Osteoartic 1981.

13 Edmonds J, Morris R I, Metzger A L, et al. Follow-up study of juvenile chronic polyarthritis with particular reference to histocompatibility antigen W.27. Ann Rheum Dis 1974; 33: 289-92.

14 Schaller J G, Ochs H D, Donnall Thomas E, et al. Histocompatibility antigens in childhood-onset arthritis. $J$ Pediatr 1976; 88: 926-30.

15 Robitaille A, Cockburn C, James D C O, et al. HLA frequencies in less common arthropathies. Ann Rheum Dis 1976; 35: 271-3. 
16 Shore A, Gladman D, Clemens L E, et al. HLA defined sub-groups of juvenile psoriatric arthritis. Abstr 0666, 15th International Congress Rheumatology. Rev Rhum Mal Osteoartic 1981.

17 Ansell B M, Wood P H N. Prognosis in juvenile chronic polyarthritis. Clin Rheum Dis 1976; 2: 397-412.

18 Williams R, Ansell B M. Radiological assessment in seropositive juvenile chronic arthritis (juvenile rheumatoid arthritis). Ann Rheum Dis 1981; 40: 526.

19 Ansell B M, Hall M A, Ribero S. A comparative study of gold

and penicillamine in seropositive juvenile chronic arthritis (juvenile rheumatoid arthritis). Ann Rheum Dis 1981; 40: 522-3.

20 Wooley P H, Griffin J, Panayi G S, et al. HLA-DR antigen and toxic reaction to sodium aurothiomalate and D-penicillamine in patients with rheumatoid arthritis. $N$ Engl $J$ Med 1980; 303: 300-2.

21 Brackertz D, Wernet P. Genetic analysis of rheumatoid arthritis: population and family studies. Arthritis Rheum 1980; 23: 656 (abstr). 